\title{
Limited Validity of $o$-Cresol and Benzylmercapturic Acid in Urine as Biomarkers of Occupational Exposure to Toluene at Low Levels
}

\author{
Osamu INOUE ${ }^{1}$, Toshio KAWAI ${ }^{2}$, Hirohiko UKAI ${ }^{3}$, Yuki MAEJIMA ${ }^{4}$, Yoshinari FUKUI ${ }^{3}$, \\ Fumiko OHASHI ${ }^{3}$, Satoru OKAMOTO ${ }^{3}$, Shiro TAKADA ${ }^{3}$, Haruhiko SAKURAI ${ }^{5}$ and \\ Masayuki IKEDA ${ }^{3 *}$
}

\author{
${ }^{1}$ Tohoku Rosai Hospital, 4-3-1 Dainohara, Aoba-ku, Sendai 981-8563, Japan \\ ${ }^{2}$ Osaka Occupational Health Service Center, Japan Industrial Safety and Health Association, Nishi-ku, Osaka \\ 550-0001, Japan \\ ${ }^{3}$ Kyoto Industrial Health Association, Nakagyo-ku, Kyoto 604-8472, Japan \\ ${ }^{4}$ Department of Hygiene, School of Medicine, Wakayama Medical University, Wakayama 641-8509, Japan \\ ${ }^{5}$ Occupational Health Research and Development Center, Japan Industrial Safety and Health Association, \\ Minato-ku, Tokyo 108-0014, Japan
}

Received November 19, 2007 and accepted February 14, 2008

\begin{abstract}
This study was initiated to evaluate $o$-cresol and benzylmercapturic acid in urine in comparison with other biomarkers, as tools to estimate the intensity of occupational exposure to toluene at low levels. In total, 108 solvent exposed workers (engaged in tape production) and 17 non-exposed controls (all men) participated in the study. The surveys were conducted in the second half of working weeks. Diffusive sampling was conducted to measure 8-h time-weighted average intensity of occupational exposure to toluene. Blood and urine samples were collected at the end of a working shift. Blood samples were subjected to analysis for toluene (Tol-B), and urine samples were analyzed for benzyl alcohol (BeOH-U), benzylmercapturic acid (BMA-U), $o$ cresol (o-CR-U), hippuric acid (HA-U) and toluene (Tol-U) by the methods previously described. The toluene concentrations in workplaces were low in general, with a geometric mean (GM) and the maximum concentration of $1.9 \mathrm{ppm}$ and $8.8 \mathrm{ppm}$, respectively. The statistical analyses of the six biomarkers for correlation with air-borne toluene showed that both Tol-B and Tol-U gave a high correlation coefficient of 0.58 to $0.61(p<0.01)$, whereas the coefficients for $\mathrm{BeOH}-\mathrm{U}$ and BMA-U together with HA-U were all low (up to 0.22 , depending on the correction for urine density) and statistically insignificant $(p>0.10)$ in most cases. $o-C R-U$ had an intermediary coefficient of $0.20(p<0.05)$. Comparison with previous publications disclosed that BeOH-U, BMA-U and HA-U correlate with toluene in air when the exposure is intense (e.g., $50 \mathrm{ppm}$ or above), but no longer proportional to air-borne toluene when the exposure is low, e.g., 2 ppm. Such appeared to be also the case for $o-C R-U$. In over-all evaluation, the validity of $o-C R-U$ in monitoring occupational exposure to toluene at low levels (e.g., 2 ppm) appear to be limited, and BMA-U is not an appropriate biomarker. BeOH-U and HA-U are also inappropriate for this purpose. Only Tol-B and Tol-U may be employed to estimate toluene exposure at low levels.
\end{abstract}

Key words: Benzyl alcohol, Benzylmercapturic acid, Biomarkers, $o$-Cresol, Hippuric acid, Occupational exposure, Toluene, Urinalysis

*To whom correspondence should be addressed. 


\section{Introduction}

Although the use of toluene in occupational setting has been gradually decreasing ${ }^{1-4}$, this aromatic solvent still maintains the leading position among solvents in various workplaces. To evaluate the exposure, biological monitoring has been conducted traditionally in terms of measuring hippuric acid concentration in the end-of-shift urine samples ${ }^{5-9}$. The focus of current concern is if the traditional biomarker of hippuric acid is still valid to monitor the exposure when the air-borne toluene concentration has been decreasing in recent years in accordance with improvements in industrial hygiene.

Comparative evaluation of recently developed biomarkers to detect occupational toluene exposure was conducted in previous two analyses to show that, whereas the traditional biomarker of hippuric acid is valid when the time-weighted average (TWA) toluene exposure is rather intense ${ }^{10)}$, this marker only poorly correlates with the exposure when toluene exposure is low, e.g., at less than $10 \mathrm{ppm}^{10,11)}$. It was also observed that un-metabolized toluene both in blood and urine is a better marker of the exposure to toluene not only at moderate levels (e.g., at $50 \mathrm{ppm}$ ) but at lower levels (e.g., $2 \mathrm{ppm})^{11)}$.

The validity of the two urinary biomarkers of $o$-cresol and benzylmercapturic acid at low toluene exposure was, however, not examined in these previous studies. It is the purpose of the present study to examine if $o$-cresol and benzylmercapturic acid are as valid as other biomarkers such as toluene in urine, when toluene exposure intensity is low.

\section{Subjects, Materials and Methods}

\section{Ethical issue}

The Ethics Committee of Kyoto Industrial Health Association approved the study protocol. The participating workers were 108 solvent-exposed workers and 17 occupationally non-exposed controls (all men) at the ages of 20 to $60 \mathrm{yr}$. They engaged in the production of adhesive tapes, and volunteered to participate in the study.

Air-borne toluene monitoring, and biological monitoring by means of urinalysis and blood analysis

The survey was conducted on the second half of working weeks following the design as previously described $^{10,11)}$. In short, TWA toluene exposure concentration was monitored by use of diffusive samplers ${ }^{12}$ ) which were placed on the working cloth (at the chest pocket level) of each worker for approximately $8 \mathrm{~h}$ (i.e., typically from 09:00 to 17:00). The carbon disulfideextract of the exposed carbon cloth was analyzed by gaschromatography); the limit of detection (LOD) for various solvents was $0.1 \mathrm{ppm}$ in common. A spot urine sample and a peripheral venous blood sample were collected from each worker at the end of the shift of the survey day. Blood samples were subjected to toluene (TolB) analysis by head-space gaschromatography with a LOD of $2 \mu \mathrm{g} / 1^{13)}$. Urine samples were analyzed for benzyl alcohol (BeOH-U, U standing for urine; LOD, 5 $\mu \mathrm{g} / 1^{14)}$ ), benzylmercapturic acid (BMA-U; LOD, $\left.0.2 \mu \mathrm{g} / 1^{15,16)}\right), o$-cresol ( $o$-CR-U; LOD, $\left.10 \mu \mathrm{g} / \mathrm{l}^{14)}\right)$, hippuric acid (HA-U; LOD, $\left.2 \mathrm{mg} / \mathrm{l}^{17}\right)$ ), and toluene in urine (Tol-U; LOD, $2 \mu \mathrm{g} / \mathrm{l}^{13)}$ ). Creatinine concentration (CR) and specific gravity (SG) were measured by colorimetry and refractometry, respectively. Biomarker levels were corrected in some cases either for creatinine concentration $^{18)}$ or for a specific gravity of urine of $1.016^{19}$. Specific gravity was expressed in terms of factor $\mathrm{G}^{20 \text { ), }}$ which was defined as factor $G=($ Specific gravity -1.000$)$ $\times 1000$.

The additiveness formula ${ }^{8,21)}$ was employed to calculate the SUM as an indicator of combined exposure to multiple solvents. For this purpose, occupational exposure limits ${ }^{22)}$ of 50, 50, 200 and $40 \mathrm{ppm}$ were taken for toluene, xylenes, ethyl acetate and hexane, respectively.

\section{Statistical analysis}

CR and SG distributed normally so that the distributions were expressed in terms of arithmetic means (AM) and arithmetic standard deviations (ASD). Toluene in air and biomarkers in blood and urine distributed log-normally, and geometric means (GM) and geometric standard deviations (GSD) were taken as representative distribution parameters. In calculating GM and GSD, the values below LOD were taken as if they were LOD/2.

Regression analyses were conducted by use of STATVIEW Version 5. When necessary, the statistical significance of the difference in two regression lines was examined by comparing paired intercepts, slopes and correlation coefficients after Ichihara ${ }^{22)}$.

\section{Results}

Levels of exposure to toluene, and that of exposure biomarkers

The exposure level of toluene in air was low with a GM of $1.9 \mathrm{ppm}$, although the GSD was large, 2.7, and the maximum toluene in air on an individual basis was nearly $9 \mathrm{ppm}$. There were co-exposures to other solvents (Table 1). However, only the exposure to ethyl acetate exceeded that to toluene when GM values were compared (i.e., 10.5 ppm vs. $1.9 \mathrm{ppm}$ ). The GM (and the maximum) of the SUM was 0.15 (1.6). The biomarker levels among the exposed group were also low, e.g., $307 \mathrm{mg} / \mathrm{l}$ $\mathrm{HA}-\mathrm{U}_{\mathrm{ob}}$ and $91 \mu \mathrm{g} / \mathrm{l} o-\mathrm{CR}-\mathrm{U}_{\mathrm{ob}}$ (Table 2). When compared 
Table 1. Solvent exposures

\begin{tabular}{lcccccc}
\hline Parameter & Ethly acetate & Ethylbenzene & Hexane & Toluene & Xylenes & SUM \\
\hline OEL $^{\text {a, b }}$ & 200 & 50 & 40 & 50 & 50 & $1^{\mathrm{c}}$ \\
$\mathrm{GM}^{\mathrm{b}}$ & 10.5 & 0.34 & 0.50 & 1.89 & 0.65 & 0.15 \\
$\mathrm{GSD}$ & 4.69 & 3.78 & 3.36 & 2.67 & 3.50 & 2.86 \\
Maximum $^{\mathrm{a}}$ & 280.3 & 11.5 & 25.1 & 8.8 & 15.9 & 1.55 \\
\hline
\end{tabular}

${ }^{a}$ Occupational exposure limits by Japan Society for Occupational Health ${ }^{21)}$.

bUnit; ppm except for the SUM which is dimensionless.

cUnity.

with the levels among the non-exposed subjects, the minimum biomarker levels among the exposed subjects were smaller than the maximum levels of the corresponding biomarkers among the non-exposed subjects in cases of $\mathrm{BeOH}-\mathrm{U}, o-\mathrm{CR}-\mathrm{U}$ and HA-U, irrespective of correction for CR or SG. It should be added that no BMA-U, Tol$\mathrm{U}$ or Tol-B were detected (i.e., $<\mathrm{LOD}$ ) among the nonexposed whereas they were detectable in almost all cases of the exposed subjects.

\section{Regression of biomarker levels with air-borne toluene}

When possible correlation of biomarker levels (as observed) with air-borne toluene was examined among the exposed subjects, the correlation coefficients were statistically significant for Tol- $\mathrm{U}_{\mathrm{ob}}$ and Tol-B ( $p<0.01$ for both) (the left half in Table 3). The coefficients for $\mathrm{BeOH}-\mathrm{U}_{\mathrm{ob}}$, BMA- $\mathrm{U}_{\mathrm{ob}}$ and $\mathrm{HA}-\mathrm{U}_{\mathrm{ob}}$ were however insignificant ( $p>0.10$, or ns). The coefficient for $o-\mathrm{CR}-\mathrm{U}_{\mathrm{ob}}, 0.202$, was statistically significant $(p<0.05)$, but this might owe to the large number of cases (i.e., $\mathrm{n}=108$ ). Correction for $\mathrm{CR}$ or SG resulted in minimum improvement in the coefficients, with no change in the stratified $p$ values. It should be added that no correction for CR or SG was applicable to Tol-B. Combination of the 17 non-exposed cases with the 108 exposed cases (the right half in Table 3) induced essentially no change; not only the correlation coefficients but the slopes and even the intercepts on the vertical axes stayed almost unchanged.

\section{Classification of biomarkers through comparison of cor- relation coefficients}

When the statistical significance of the difference between any two correlation coefficients for the exposed group were examined for 15 pairs among the six biomarkers (Table 4), it was possible to classify the six biomarkers into two groups, i.e., two (Tol- $\mathrm{U}_{\mathrm{ob}}$ and Tol-B) with high coefficients and four $\left(o-C R-\mathrm{U}_{\mathrm{ob}}, \mathrm{BeOH}-\mathrm{U}_{\mathrm{ob}}\right.$, BMA- $\mathrm{U}_{\mathrm{ob}}$ and $\mathrm{HA}-\mathrm{U}_{\mathrm{ob}}$ ) with low coefficients. For example, 'ns' at the cross of the 'Tol-B' column and the 'Tol$\mathrm{U}_{\mathrm{ob}}$ ' line means that the difference between the two coefficients of correlation with air-borne toluene, 0.613 for Tol- $\mathrm{U}_{\mathrm{ob}}$ and 0.575 for Tol-B, was statistically insignifi- cant ( $p>0.10$ ), whereas ' $<0.01$ ' at the cross of the ' $o$-CR$\mathrm{U}_{\mathrm{ob}}$ ' column and the 'Tol- $\mathrm{U}_{\mathrm{ob}}$ ' line means that the difference between the two coefficients, 0.613 for Tol- $\mathrm{U}_{\mathrm{ob}}$ and 0.202 for $o-\mathrm{CR}-\mathrm{U}_{\mathrm{ob}}$, was in fact significant $(p<0.01)$. Thus, no significant difference $(p>0.10)$ was detected between the former two or among the latter four. The analyses with 10 pairs each of CR- or SG-corrected biomarkers (no correction was applicable to Tol-B) gave exactly the same results.

For visual understanding of the difference between biomarkers with high and low correlation coefficients, Tol$\mathrm{U}_{\mathrm{ob}}$ (with a high correlation coefficient) $o-\mathrm{CR}-\mathrm{U}_{\mathrm{ob}}$ and BMA- $\mathrm{U}_{\mathrm{ob}}$ (with low coefficients) were selected as typical cases, and scatter diagrams (with 95\% confidence intervals) against air-borne toluene were depicted in Fig. 1. It is clear that the $95 \%$ confidence interval was narrower for Tol- $\mathrm{U}_{\mathrm{ob}}$ than that for $o-\mathrm{CR}-\mathrm{U}_{\mathrm{ob}}$ or BMA$\mathrm{U}_{\mathrm{ob}}$.

\section{Discussion}

The present analysis on 108 workers occupationally exposed to toluene at $1.9 \mathrm{ppm}$ as GM $(8.8 \mathrm{ppm}$ as the maximum; Table 1) made it clear that both $\mathrm{Tol}-\mathrm{U}_{\mathrm{ob}}$ and Tol-B correlate closely ( $r=0.61$ and 0.58 , respectively; $p<0.01$ for both) with toluene exposure concentration even at such low levels. The correlation of $o-\mathrm{CR}-\mathrm{U}_{\mathrm{ob}}$ was less significant with $r=0.20$ and $p<0.05$, whereas $\mathrm{BeOH}-\mathrm{U}_{\mathrm{ob}}$ and BMA- $\mathrm{U}_{\mathrm{ob}}$ did not correlate significantly $(r=0.16$ and 0.11 , respectively, with $p>0.10$ for both; Table 3 ). In the two previous studies, one ${ }^{10}$ with toluene exposure at moderate levels (at $10 \mathrm{ppm}$ as GM and at $121 \mathrm{ppm}$ as the maximum) and the other ${ }^{11}$ at low levels (at $1.6 \mathrm{ppm}$ as GM and $26.5 \mathrm{ppm}$ as the maximum), Tol-U correlated with TWA toluene concentrations in air not only at moderate levels but at low levels. No Tol-B was examined in the moderate exposure study ${ }^{10)}$, but separate studies showed that Tol-B significantly correlates with air-borne toluene at low levels ${ }^{11}$ ) as well as at high levels (the maximum level being $132 \mathrm{ppm})^{23)}$. Nise ${ }^{24)}$ also reported a high coefficient (0.84) for correlation of Tol-B with airborne toluene. Thus, the close relationship of Tol- $\mathrm{U}_{\mathrm{ob}}$ 
Table 2. Levels of toluene exposure and resulting levels of biomarkers

\begin{tabular}{|c|c|c|c|c|c|c|c|c|c|c|c|}
\hline Group & $\begin{array}{l}\text { Correction for } \\
\text { Parameter }\end{array}$ & $\begin{array}{c}\text { Tol } \\
\text { in air } \\
(\mathrm{ppm})\end{array}$ & SUM $^{\mathrm{a}}$ & $\begin{array}{l}\mathrm{CR} \\
(\mathrm{g} / \mathrm{l})\end{array}$ & G & $\begin{array}{l}\mathrm{BeOH}-\mathrm{U} \\
\quad(\mu \mathrm{g} / \mathrm{l} \\
\text { or } \mathrm{g} \mathrm{cr})\end{array}$ & $\begin{array}{l}\text { BMA-U } \\
\quad(\mu \mathrm{g} / 1 \\
\text { or g cr })\end{array}$ & $\begin{array}{c}o-\mathrm{CR}-\mathrm{U} \\
(\mu \mathrm{g} / 1 \\
\text { or } \mathrm{g} \mathrm{cr})\end{array}$ & $\begin{array}{c}\text { HA-U } \\
(\mathrm{mg} / 1 \\
\text { or } \mathrm{g} \mathrm{cr})\end{array}$ & $\begin{array}{c}\text { Tol-U } \\
(\mu \mathrm{g} / 1 \\
\text { or } \mathrm{g} \mathrm{cr})\end{array}$ & $\begin{array}{l}\text { Tol-B } \\
(\mu \mathrm{g} / \mathrm{l})\end{array}$ \\
\hline \multicolumn{12}{|c|}{ Exposed (108 cases) } \\
\hline \multicolumn{12}{|c|}{ None (i.e., as observed) } \\
\hline & $\mathrm{GM}^{\mathrm{b}}$ & 1.89 & 0.15 & 1.64 & 23 & 46 & 2.07 & 91 & 307 & 4.22 & 14.8 \\
\hline & $\mathrm{GSD}^{\mathrm{b}}$ & 2.67 & 2.86 & 0.85 & 6 & 2.47 & 7.26 & 3.28 & 2.58 & 1.90 & 2.31 \\
\hline & MED & 2.20 & 0.17 & 1.47 & 23 & 43 & 2.60 & 105 & 330 & 4.11 & 13.3 \\
\hline & Min & 0.2 & 0.01 & 0.32 & 7 & 6 & $<\mathrm{LOD}^{\mathrm{c}}$ & $<\mathrm{LOD}^{\mathrm{c}}$ & 48 & $<\mathrm{LOD}^{\mathrm{c}}$ & 2.3 \\
\hline & Max & 8.8 & 1.6 & 4.42 & 39 & 453 & 94.4 & 1102 & 2571 & 17.00 & 103.0 \\
\hline \multicolumn{12}{|c|}{ Creatinine } \\
\hline & GM & & & & & 32 & 1.45 & 63 & 214 & 2.95 & \\
\hline & GSD & & & & & 2.44 & 8.34 & 3.75 & 2.28 & 2.09 & \\
\hline & MED & & & & & 29 & 1.67 & 72 & 213 & 2.80 & \\
\hline & Min & & & & & 5 & $<\mathrm{LOD}^{\mathrm{c}}$ & $<\mathrm{LOD}^{\mathrm{c}}$ & 35 & $<\mathrm{LOD}^{\mathrm{c}}$ & \\
\hline & Max & & & & & 440 & 91.6 & 1192 & 1546 & 17.60 & \\
\hline \multicolumn{12}{|c|}{ Specific gravity (1.016) } \\
\hline & GM & & & & & 34 & 1.51 & 66 & 223 & 3.08 & \\
\hline & GSD & & & & & 2.34 & 7.57 & 3.45 & 2.36 & 1.88 & \\
\hline & MED & & & & & 30 & 1.72 & 77 & 239 & 2.99 & \\
\hline & Min & & & & & 4 & $<\mathrm{LOD}^{\mathrm{c}}$ & $<\mathrm{LOD}^{\mathrm{c}}$ & 36 & $<\mathrm{LOD}^{\mathrm{c}}$ & \\
\hline & $\operatorname{Max}$ & & & & & 315 & 75.5 & 840 & 1469 & 12.19 & \\
\hline \multicolumn{12}{|c|}{ Non-exposed controls (17 cases) } \\
\hline \multicolumn{12}{|c|}{ None (i.e., as observed) } \\
\hline & $\mathrm{GM}^{\mathrm{b}}$ & & & 1.45 & 23 & 55 & $<\mathrm{LOD}^{\mathrm{c}}$ & 75 & 224 & $<\mathrm{LOD}^{\mathrm{c}}$ & $<\mathrm{LOD}^{\mathrm{c}}$ \\
\hline & $\mathrm{GSD}^{\mathrm{b}}$ & & & 0.78 & 7 & 2 & & 3 & 3 & & \\
\hline & MED & & & 1.48 & 23 & 56 & & 63.2 & 250 & & \\
\hline & Min & & & 0.52 & 10 & 16 & & 5 & 30 & & \\
\hline & Max & & & 3.03 & 39 & 162 & & 386 & 1580 & & \\
\hline \multicolumn{12}{|c|}{ Creatinine } \\
\hline & GM & & & & & 44 & & 60 & 180 & & \\
\hline & GSD & & & & & 1.77 & & 2.86 & 2.23 & & \\
\hline & MED & & & & & 42 & & 66 & 187 & & \\
\hline & Min & & & & & 16 & & 10 & 42 & & \\
\hline & $\operatorname{Max}$ & & & & & 161 & & 412 & 940 & & \\
\hline \multicolumn{12}{|c|}{ Specific gravity (1.016) } \\
\hline & GM & & & & & 41 & & 55 & 165 & & \\
\hline & GSD & & & & & 1.63 & & 3.07 & 2.56 & & \\
\hline & MED & & & & & 39 & & 58 & 187 & & \\
\hline & Min & & & & & 15 & & 5 & 28 & & \\
\hline & Max & & & & & 109 & & 362 & 903 & & \\
\hline
\end{tabular}

Abbreviations are: BeOH-U, benzyl alcohol in urine; BMA-U, benzylmercapturic acid in urine; $o$-CR, $o$-cresol in urine;

HA-U, hippuric acid in urine; Tol-U, toluene in urine and Tol-B, toluene in blood.

aSum after the additiveness formula (for details, see the Materials and Methods section).

${ }^{b} \mathrm{AM}$ and ASD in cases of CR (creatinine) and G (Factor G; for details, see the Materials and Methods section).

'Less than the limit of detection; for the value, see the Materials and Methods section. 
Table 3. Correlation of biomarkers with toluene in aira

\begin{tabular}{|c|c|c|c|c|c|c|c|c|c|}
\hline \multirow{2}{*}{$\begin{array}{c}\text { Correction for } \\
\text { Biomarker }\end{array}$} & \multirow[b]{2}{*}{ (unit) } & \multicolumn{4}{|c|}{ Exposed group ${ }^{\mathrm{b}}$} & \multicolumn{4}{|c|}{ Exposed group + non-exposed group ${ }^{c}$} \\
\hline & & Intercept $^{\mathrm{d}}$ & Slope & $r^{\mathrm{f}}$ & $p^{\mathrm{g}}$ & Intercept ${ }^{d}$ & Slope & $r^{\mathrm{f}}$ & $p^{\mathrm{g}}$ \\
\hline \multicolumn{10}{|c|}{ None (i.e., as observed) } \\
\hline $\mathrm{BeOH}-\mathrm{U}_{\mathrm{ob}}$ & $(\mu \mathrm{g} / \mathrm{l})$ & 55.4 & 5.79 & 0.161 & $\mathrm{~ns}^{\mathrm{h}}$ & 57.4 & 5.35 & 0.161 & $\mathrm{~ns}^{\mathrm{h}}$ \\
\hline BMA-U ${ }_{\mathrm{ob}}$ & $(\mu \mathrm{g} / 1)$ & 6.8 & 0.83 & 0.114 & $n s^{\mathrm{h}}$ & 4.9 & 1.25 & 0.184 & $<0.10$ \\
\hline$o-\mathrm{CR}-\mathrm{U}_{\mathrm{ob}}$ & $(\mu \mathrm{g} / \mathrm{l})$ & 111.7 & 14.92 & 0.202 & $<0.05$ & 115.0 & 14.22 & 0.202 & $<0.05$ \\
\hline $\mathrm{HA}-\mathrm{U}_{\mathrm{ob}}$ & $(\mathrm{mg} / \mathrm{l})$ & 454.1 & 2.70 & 0.014 & $n s^{h}$ & 431.8 & 7.46 & 0.045 & $\mathrm{~ns}^{\mathrm{h}}$ \\
\hline Tol- $\mathrm{U}_{\mathrm{ob}}$ & $(\mu \mathrm{g} / \mathrm{l})$ & 2.5 & 0.93 & 0.613 & $<0.01$ & 1.8 & 1.08 & 0.688 & $<0.01$ \\
\hline Tol-B & $(\mu \mathrm{g} / \mathrm{l})$ & 7.9 & 4.53 & 0.575 & $<0.01$ & 5.7 & 5.01 & 0.643 & $<0.01$ \\
\hline \multicolumn{10}{|l|}{ Creatinine } \\
\hline $\mathrm{BeOH}-\mathrm{U}_{\mathrm{cr}}$ & $(\mu \mathrm{g} / \mathrm{g} \mathrm{cr})$ & 33.2 & 6.42 & 0.217 & $<0.05$ & 39.9 & 4.01 & 0.176 & $<0.10$ \\
\hline BMA-U $\mathrm{err}_{\mathrm{c}}$ & $(\mu \mathrm{g} / \mathrm{g} \mathrm{cr})$ & 5.4 & 0.71 & 0.118 & $\mathrm{~ns}^{\mathrm{h}}$ & 3.8 & 0.87 & 0.173 & $<0.10$ \\
\hline$o-\mathrm{CR}-\mathrm{U}_{\mathrm{cr}}$ & $(\mu \mathrm{g} / \mathrm{g} \mathrm{cr})$ & 75.1 & 17.51 & 0.228 & $<0.05$ & 84.5 & 10.93 & 0.210 & $<0.05$ \\
\hline $\mathrm{HA}-\mathrm{U}_{\mathrm{cr}}$ & (mg/g cr) & 276.5 & 7.12 & 0.063 & $\mathrm{~ns}^{\mathrm{h}}$ & 288.2 & 6.54 & 0.055 & $n s^{\mathrm{h}}$ \\
\hline Tol- $\mathrm{U}_{\mathrm{cr}}$ & $(\mu \mathrm{g} / \mathrm{g} \mathrm{cr})$ & 1.4 & 0.87 & 0.607 & $<0.01$ & 1.3 & 0.79 & 0.696 & $<0.01$ \\
\hline \multicolumn{10}{|c|}{ Specific gravity } \\
\hline $\mathrm{BeOH}-\mathrm{U}_{\mathrm{sg}}$ & $(\mu \mathrm{g} / \mathrm{l})$ & 37.6 & 4.50 & 0.182 & $<0.10$ & 38.7 & 5.26 & 0.190 & $\fallingdotseq 0.05$ \\
\hline BMA-U ${ }_{\mathrm{sg}}$ & $(\mu \mathrm{g} / \mathrm{l})$ & 5.3 & 0.55 & 0.100 & $n s^{\mathrm{h}}$ & 3.7 & 1.04 & 0.190 & $\fallingdotseq 0.05$ \\
\hline$o-\mathrm{CR}-\mathrm{U}_{\mathrm{sg}}$ & $(\mu \mathrm{g} / \mathrm{l})$ & 81.8 & 11.50 & 0.210 & $<0.05$ & 81.1 & 16.24 & 0.226 & $<0.05$ \\
\hline $\mathrm{HA}-\mathrm{U}_{\mathrm{sg}}$ & $(\mathrm{mg} / \mathrm{l})$ & 307.9 & 2.33 & 0.020 & $\mathrm{~ns}^{\mathrm{h}}$ & 267.0 & 9.15 & 0.084 & $n s^{h}$ \\
\hline Tol- $U_{\text {sg }}$ & $(\mu \mathrm{g} / \mathrm{l})$ & 1.8 & 0.69 & 0.623 & $<0.01$ & 1.0 & 0.96 & 0.672 & $<0.01$ \\
\hline
\end{tabular}

Abbreviations are as under Table 1.

a Simple regression taking toluene in air as a dependent variable and the corresponding biomarker as a dependent variable.

${ }^{\mathrm{b}} 108$ cases.

${ }^{\mathrm{c}} \mathrm{A}$ combination of 108 exposed cases and 17 non-exposed cases.

dUnit as given for each biomarker.

eUnit; the unit for each biomarker/ppm.

${ }^{\mathrm{f}}$ Correlation coefficient.

$\mathrm{g}_{\mathrm{p}}$ for correlation coefficient.

${ }^{\mathrm{h}}$ not significant $(p>0.10)$.

Table 4. Comparison of two correlation coefficients

\begin{tabular}{|c|c|c|c|c|c|c|}
\hline \multirow{2}{*}{ Biomarker } & \multirow{2}{*}{$r$} & \multicolumn{5}{|c|}{$p$ for the difference in correlation coefficient $(r)$ between two biomarkers } \\
\hline & & Tol-B & $o-\mathrm{CR}-\mathrm{U}_{\mathrm{ob}}$ & $\mathrm{BeOH}-\mathrm{U}_{\mathrm{ob}}$ & BMA-U $\mathrm{U}_{\mathrm{ob}}$ & $\mathrm{HA}-\mathrm{U}_{\mathrm{ob}}$ \\
\hline Tol- $U_{o b}$ & 0.613 & ns & $<0.01$ & $<0.01$ & $<0.01$ & $<0.01$ \\
\hline Tol-B & 0.575 & & $<0.01$ & $<0.01$ & $<0.01$ & $<0.01$ \\
\hline$o-\mathrm{CR}-\mathrm{U}_{\mathrm{ob}}$ & 0.202 & & & ns & ns & ns \\
\hline $\mathrm{BeOH}-\mathrm{U}_{\mathrm{ob}}$ & 0.161 & & & & ns & ns \\
\hline BMA-U ${ }_{\mathrm{ob}}$ & 0.114 & & & & & ns \\
\hline $\mathrm{HA}-\mathrm{U}_{\mathrm{ob}}$ & 0.014 & & & & & \\
\hline
\end{tabular}

Abbreviations are as under Table 2.

ns stands for $p>0.10$.

and Tol-B with toluene in air is in a good agreement with previous studies.

A close correlation $(r=0.80)$ with toluene in air was reported for $\mathrm{BeOH}-\mathrm{U}_{\mathrm{ob}}$ in a factory survey in which workers were exposed to toluene at $12.6 \mathrm{ppm}$ and $130 \mathrm{ppm}$ as the maximum ${ }^{11)}$. Similarly, the correlation was high when toluene exposure was intense (i.e., 15 ppm as GM and $70 \mathrm{ppm}$ as the maximum), but it was substantially less close otherwise ${ }^{10)}$. Thus, the present observation of low correlation ( $r=0.16$ with $p>0.10$ ) is on line with the previous observation of poor correlation when toluene exposure was low ${ }^{10)}$. With regard to HA-U, it was in fact a highlight of the observations in the previous two studies $^{10,11)}$ that the correlation with air-borne toluene was high and low, respectively, when the GM exposure was in excess of e.g., $10 \mathrm{ppm}$ and less than $2 \mathrm{ppm}$. The present low correlation at low toluene exposure levels confirms the previous finding after low level toluene exposure, although this biomarker has been long used when toluene in workroom air was high $5,6,25,26)$. 
a.

Tol in air vs. Tol- $\mathrm{U}_{\mathrm{ob}}$

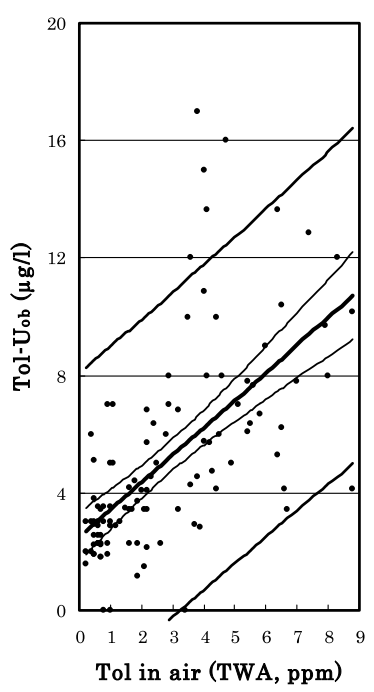

b.

Tol in air vs. $o-\mathrm{CR}-\mathrm{U}_{\mathrm{ob}}$

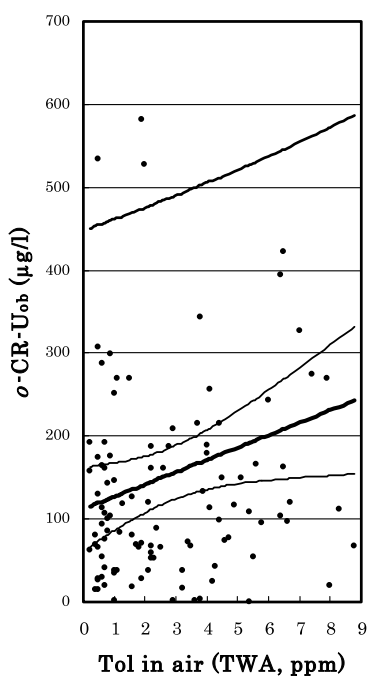

c.

Tol in air vs. BMA-U

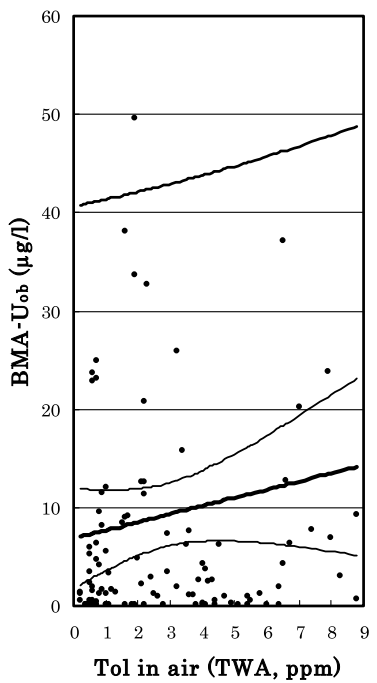

Fig. 1. Scatter diagrams to show correlation of a. toluene in urine as observed (Tol- $\left.\mathrm{U}_{\mathrm{ob}}\right)$, b. $o$-cresol in urine (as observed; $o-C R-U_{o b}$ ) and c. benzylmercapturic acid in urine (as observed; BMA- $\mathrm{U}_{\mathrm{ob}}$ ) with time-weighted average concentrations of toluene in air (Tol in air).

Thick lines in the center of figures are calculated regression lines. The curves on both sides of the lines and the outer-most curves indicate the $95 \%$ confidence ranges of the means and the individual values, respectively. Each dot represents an exposed case. For the equations of the regression lines, see Table 3.

BMA-U and $o$-CR-U may need detailed discussion as these two markers were not evaluated in the previous low exposure survey ${ }^{11)}$. Maestri et al. ${ }^{27)}$ observed a high correlation coefficient of 0.74 for BMA when they examined 18 workers who were exposed to toluene up to $65 \mathrm{ppm}$. In a study on 46 solvent-exposed workers (all men) with toluene exposure at $13 \mathrm{ppm}$ as GM (86 ppm as the maximum), Inoue et al. ${ }^{15)}$ observed that the correlation coefficient of BMA- $\mathrm{U}_{\mathrm{ob}}$ with toluene in air was as high as $0.66(p<0.01)$. Inoue et al. ${ }^{16)}$ further observed, in a separate survey with 122 male printers who were exposed to toluene at $8.3 \mathrm{ppm}$ as GM and $86.4 \mathrm{ppm}$ as the maximum, that BMA- $\mathrm{U}_{\mathrm{ob}}$ correlated closely with toluene in air with a correlation coefficient of 0.73 , the coefficient being greater than that for $\mathrm{HA}-\mathrm{U}_{\mathrm{ob}}(0.58)$ or $o-\mathrm{CR}-\mathrm{U}_{\mathrm{ob}}(0.63)$. Nevertheless, the coefficient for BMA-U tended to be high (e.g., 0.57) only when toluene exposure was rather intense (e.g., $15 \mathrm{ppm}$ as GM and $70 \mathrm{ppm}$ as the maximum) but low and insignificant after low level exposures ${ }^{10)}$. The latter negative observation was well reproduced in the present study (Table 3 ).

High correlation of $o-\mathrm{CR}-\mathrm{U}$ had been attracting attention with the expectation that this metabolite could be a better surrogate of HA-U for toluene biological monitoring ${ }^{24,27)}$. For example, De Rosa et al. ${ }^{29)}$ observed a high correlation coefficient of 0.78 for $o-\mathrm{CR}-\mathrm{U}_{\mathrm{cr}}$ among 14 workers exposed to toluene up to $61 \mathrm{ppm}$. The same group $^{30)}$ obtained a similarly high coefficient of 0.79 for
$o-\mathrm{CR}-\mathrm{U}_{\mathrm{cr}}$ among 18 printers exposed to up to $59 \mathrm{ppm}$. Nise $^{23)}$ observed a correlation coefficient of 0.57 for $o$ $\mathrm{CR}-\mathrm{U}_{\mathrm{cr}}$ in a factory survey in which 58 workers were exposed to toluene at $25.6 \mathrm{ppm}$ as a median and $132 \mathrm{ppm}$ as the maximum. The correlation was in fact closer than that for $\mathrm{HA}-\mathrm{U}_{\mathrm{cr}}(0.37)$. Similar correlation coefficients of $0.52^{13)}, 0.70^{31)}$ and $0.65^{32}$ ) were observed in studies on solvent workers exposed to $3.9 \mathrm{ppm}$ (as GM; $100 \mathrm{ppm}$ as the maximum), $25 \mathrm{ppm}$ (as GM), and $63 \mathrm{ppm}$ (median), respectively. Recently, Fustinoni et al. ${ }^{33)}$ studied 38 printers exposed to $12.8 \mathrm{ppm}$ as GM (43.2 $\mathrm{ppm}$ as the maximum). The regression analysis after logarithmic conversion of both toluene in air and $o$-CR-U gave a coefficient of 0.70 for $o-\mathrm{CR}-\mathrm{U}_{\mathrm{cr}}$. This study group also found even a higher coefficient of 0.88 in a group of 122 solvent workers exposed to toluene at 14 ppm as GM (62 ppm as the maximum $)^{10)}$. Thus, sufficiently high correlation coefficients were obtained for $o$-CR-U in various studies in which toluene exposure was high. Nevertheless, a very low coefficient of 0.17 was also observed in a plant where the GM toluene in air was $2.1 \mathrm{ppm}(9.3 \mathrm{ppm}$ as the maximum) ${ }^{10)}$. The present observation of $r=0.20$ (Table 3 ) is apparently similar to the latter value of 0.17 . It appears likely that this biomarker may correlate closely with toluene in air under the condition of intensive exposure, but not necessarily so when the exposure is less intense.

With regard to possible confounders of toluene metabolism, it should be noted that workers in the present study 
were not only exposed to toluene but to other solvents although at low concentrations, e.g., below the current occupational exposure limits ${ }^{21}$ (with one exception of ethyl acetate; Table 1). It is known that no $\mathrm{BeOH}$, BMA, $\mathrm{HA}$ or Tol will be formed after inhalation of ethylbenzene, hexane or xylenes ${ }^{34)}$, and that ethyl acetate will be quickly hydrolyzed in vivo by ubiquitous esterase and then mineralized ${ }^{35)}$. It is also known that no metabolic interaction will take place between organic solvents when the exposures are low, e.g., below occupational exposure limits ${ }^{36,37)}$. In fact, no metabolic modification was detected among workers exposed to toluene in combination with xylenes ${ }^{38-40)}$, hexane ${ }^{41)}$ or ethyl acetate ${ }^{42)}$ at the concentrations below respective occupational exposure limits. Thus, chances should be very remote for the present study that toluene metabolism was modified by other solvents co-exposed. It was previously observed that metabolism of toluene will not be modified by social drinking ${ }^{38)}$. In contrast, metabolism of toluene and that of xylenes were suppressed by smoking ${ }^{38,39)}$. It was not possible, however, to confirm this effect in the present study as no data were available on the smoking habits.

In over-all evaluation, therefore, it appears prudent to conclude that un-metabolized toluene in blood and urine (i.e., Tol-B and Tol-U) correlate with toluene exposure even at low levels such as $1.9 \mathrm{ppm}$ as GM and $8.8 \mathrm{ppm}$ as the maximum. In contrast, BMA-U, BeOH-U and HA$\mathrm{U}$ may not be applicable as exposure biomarkers when toluene exposure is low. The value of $o$-CR-U also appears to be limited under low toluene exposure.

\section{Acknowledgements}

The authors are grateful to the administrations and staffs of Tohoku Rosai Hospital, Sendai, Japan, Osaka Occupational Health Service Center, Japan Industrial Safety and Health Association, Osaka, Japan, and Kyoto Industrial Health Association, Kyoto, Japan for their interest in and support to this work.

\section{References}

1) Ukai $H$, Inui $S$, Takada $S$, Dendo J, Ogawa J, Isobe $K$, Ashida T, Tamura M, Tabuki K, Ikeda M (1997) Types of organic solvents used in small- to medium-scale industries in Japan; a nation-wide field survey. Int Arch Occup Environ Health 70, 385-592.

2) Yasugi T, Endo G, Monna T, Odachi T, Yamaoka K, Kawai T, Horiguchi S, Ikeda M (1998) Types of organic solvents used in workplaces and work environment conditions with special references to reproducibility of work environment classification. Ind Health 36, 223-33.

3) Moon C-S, Lee J-T, Chun J-H, Ikeda M (2001) Use of solvents in industries in Korea; experience in
Sinpyeong-Jangrim industrial complex. Int Arch Occup Envion Health 74, 148-52.

4) Samoto H, Fukui Y, Ukai H, Okamoto S, Takada S, Ohashi F, Moriguchi J, Ezaki T, Ikeda M (2006) Field survey on types of organic solvents used in enterprises of various sizes. Int Arch Occup Environ Health 79, 558-67.

5) Ikeda M, Ohtsuji H (1969) Significance of urinary hippuric acid determination as an index of toluene exposure. Br J Ind Med 26, 244-6.

6) Lauwerys R (1983) Toluene. In: Human biological monitoring of industrial chemicals, Vol. 1, Alessio L, Berlin A, Roi R and Boni M (Eds.), 159-75. Joint Research Centre Ispra Establishment, CEC, Ispra.

7) Lauwerys RR, Hoet P (2001) Industrial chemical exposure, 3rd Ed., 219, Lewis Publishers, Boca Ration.

8) American Conference of Governmental Industrial Hygienists (2006) TLVs and BEIs; Toluene in the 2006 Notice of intended changes, ACGIH, Cincinnati.

9) Deutsche Forschungsgemeinschaft (2006) List of MAK and BAT values, 2006, Wiley-VCH, Weinheim.

10) Ukai H, Kawai $T$, Inoue $O$, Maejima $Y$, Fukui $Y$, Ohashi F, Okamoto S, Takada S, Sakurai H, Ikeda M (2007) Comparative evaluation of biomarkers of occupational exposure to toluene. Int Arch Occup Environ Health 81, 81-93.

11) Kawai $T$, Ukai $H$, Inoue $O$, Maejima $Y$, Fukui $Y$, Ohashi F, Okamoto S, Takada S, Sakurai H, Ikeda M (2007) Evaluation of biomarkers of occupational exposure to toluene at low levels. Int Arch Occup Environ Health 81, 253-62.

12) Hirayama T, Ikeda M (1979) Applicability of activated carbon felt to the dosimetry of solvent vapor mixture. Am Ind Hyg Ass J 40, 1091-6.

13) Kawai T, Mizunuma K, Okada $Y$, Horiguchi S, Ikeda M (1996) Toluene itself as the best urinary marker of toluene exposure. Int Arch Occup Environ Health 68, 289-97.

14) Kawai T, Yamauchi T, Miyama Y, Sakurai H, Ukai H, Takada S, Ohashi F, Ikeda M (2007) Benzyl alcohol as a marker of occupational exposure to toluene. Ind Health 45, 143-50.

15) Inoue $\mathrm{O}$, Kanno E, Yusa $\mathrm{T}$, Kakizaki M, Ukai H, Okamoto S, Higashikawa K, Ikeda M (2002) Urinary benzylmercapturic acid as a marker of occupational exposure to toluene. Int Arch Occup Environ Health 75, 341-7.

16) Inoue O, Kanno E, Kasai K, Ukai H, Okamoto S, Ikeda M (2004) Benzylmercapturic acid is superior to hippuric acid and $o$-cresol as a urinary marker of occupational exposure to toluene. Toxicol Lett 147, 177-86.

17) Ogata M, Taguchi $T$ (1987) Quantitation of urinary metabolites of toluene, xylene, styrene, ethylbenzene, benzene and phenol by automated high performance liquid chromatography. Int Arch Occup Environ Health 59, 263-72.

18) Jackson S (1966) Creatinine in urine as an index of uri- 
nary excretion rate. Health Phys 12, 341-50.

19) Rainsford SG, Lloyd Davies TA (1965) Urinary excretion of phenol by men exposed to benzene; a screening test. Br J Ind Med 22, 21-6.

20) Levine L, Fahy JP (1945) Evaluation of urinary lead concentrations. I. The significance of the specific gravity. J Ind Hyg Toxicol 27, 217-23.

21) Japan Society for Occupational Health (2007) Recommendation of occupational exposure limits (2007-2008). J Occup Health 49, 328-44.

22) Ichihara K (1990) Comparison of two regression parameters. In: Statistics for bioscience, 218-23, Nankodo Publishers, Tokyo (in Japanese).

23) Kawai T, Mizunuma K, Yasugi T, Horiguchi S, Ikeda M (1994) Toluene in blood as a marker of choice for low-level exposure to toluene. Int Art Occup Environ Health 66, 309-15.

24) Nise G (1992) Urinary excretion of $o$-cresol and hippuric acid after toluene exposure in rotogravure printing. Int Arch Occup Envion Health 63, 377-81.

25) Hasegawa K, Shiojima S, Koizumi A, Ikeda M (1983) Hippuric acid and $o$-cresol in the urine of workers exposed to toluene. Int Arch Occup Environ Health 52, 197-208.

26) Ikeda M (1996) Chapter 4. Selected solvents. 4.6 Toluene. In: Biological monitoring of chemical exposure in the workplace. Vol. 1, Mikheev MI (Ed.), 205-17, World Health Organization, Geneva.

27) Maestri L, Ghittori S, Imbriani M (1997) Determination of specific mercapturic acids as an index of exposure to environmental benzene, toluene, and styrene. Ind Health 35, 489-501.

28) Truchon G, Tardif R, Brodeur J (1999) o-Cresol: a good indicator of exposure to low levels of toluene. Appl Occup Environ Hyg 14, 677-81.

29) De Rosa E, Brugnone F, Bartolucci GB, Perbellini L, Bellomo ML, Gori GP, Sigon M, Corona PC (1985) The validity of urinary metabolites as indicators of low exposures to toluene. Int Arch Occup Environ Health 56, 135-45.

30) De Rosa E, Bartolucci GB, Sigon M, Callegaro R, Perbellini L, Brugnone F (1987) Hippuric acid and ortho-cresol as biological indicators of occupational exposure to toluene. Am J Ind Med 11, 529-37.

31) Inoue $O$, Seiji $K$, Watanabe $T$, Chen $Z$, Huang $M-Y$, Xu X-P, Qiao X, Ikeda M (1994) Effects of smoking and drinking habits on urinary $o$-cresol excretion after occupational exposure to toluene vapor among Chinese workers. Am J Ind Med 25, 697-708.
32) Angerer J, Schildbach M, Krämer A (1998) S-pToluylmercapturic acid in the urine of workers exposed to toluene: a new biomarker for toluene exposure. Arch Toxicol 72, 119-23.

33) Fustinoni S, Mercadante R, Campo L, Scibetta L, Valla C, Constanti D, Foá V (2007) Comparison between urinary $o$-cresol and toluene as biomarkers of toluene exposure. J Occup Environ Hyg 4, 1-9.

34) American Conference of Governmental Industrial Hygienists (2007) Documentation of the $\mathrm{TLVs}^{\circledR}$ and BEIs ${ }^{\circledR}, 2007$. BEI for Ethylbenzene, Hexane, Toluene and Xylenes. ACGIH, Cincinnati.

35) Browning E (1965) Ethyl acetate. In: Toxicity and metabolism of industrial solvents, 522-5, Elsevier, Amsterdam, London and New York.

36) Ikeda M (1983) Interactions and health aspects of exposure to mixtures of organic solvents. In: Health effects of combined exposures to chemicals in work and community environments, Andrzejewski SW and Tarkowski S (Eds.), 77-97, WHO Regional Office for Europe, Copenhagen.

37) Ikeda M (1995) Exposure to complex mixtures: implications for biological monitoring. Toxicol Lett 77, 85-91.

38) Huang M-Y, Jin C, Liu Y-T, Li B-H, Qu Q-S, Uchida Y, Inoue O, Nakatsuka H, Watanabe T, Ikeda M (1994) Exposure of workers to a mixture of toluene and xylenes. I. Metabolism. Occup Environ Med 51, 42-6.

39) Inoue O, Seiji K, Kawai T, Watanabe T, Jin C, Cai S-X, Chen Z, Qu Q-S, Zhang T, Ikeda M (1993) Excretion of methylhippuric acids in urine of workers exposed to a xylene mixture: comparison among three xylene isomers and toluene. Int Arch Occup Environ Health 64, 533-9.

40) Takeuchi A, Kawai T, Zhang Z-W, Miyama Y, Sakamoto K, Higashikawa K, Ikeda M (2002) Toluene, xylenes, and xylene isomers in urine as biological indicators of low-level exposure to each solvent; a comparative study. Int Arch Occup Environ Health 75, 387-93.

41) Kawai T, Miyama Y, Horiguchi S, Sakamoto K, Zhang Z-W, Higashikawa K, Ikeda M (2000) Possible metabolic interaction between hexane and other solvents coexposed at sub-occupational exposure limit levels. Int Arch Occup Environ Health 73, 449-56.

42) Ukai H, Takada S, Inui S, Imai $Y$, Kawai T, Shimbo S, Ikeda M (1994) Occupational exposure to solvent mixtures: effects on health and metabolism. Occup Environ Med 51, 523-9. 